\title{
INTERAÇÃO ENTRE INSETICIDA ORGANOFOSFORADO E HERBICIDAS INIBIDORES DA PROTOX E SUA IMPLICAÇÃO NA RESISTÊNCIA DE Euphorbia heterophylla
}

\section{INTERACTION BETWEEN ORGANOPHOSPHATE INSECTICIDE AND PROTOX- INHIBITING HERBICIDES AND ITS IMPLICATION IN THE RESISTANCE OF Euphorbia heterophylla}

\author{
Michelangelo Muzell TREZZI ${ }^{1}$ \\ Anderson Luis NUNES ${ }^{2}$ \\ Emerson da Silva PORTES ${ }^{3}$
}

\begin{abstract}
RESUMO
A metabolização dos herbicidas é um dos mecanismos que conferem resistência aos herbicidas em plantas daninhas. Inseticidas organofosforados inibem as enzimas que são responsáveis pela metabolização de herbicidas. 0 objetivo desse trabalho foi identificar se a metabolização de herbicidas inibidores da PROTOX é a causa da resistência a esse mecanismo de ação em biótipo de Euphorbia heterophylla com resistência múltipla a inibidores da ALS e PROTOX. O delineamento experimental foi o completamente casualizado, com tratamentos organizados em esquema fatorial, com 4 repetições, em que o fator $A$ consistiu dos biótipos de $E$. heterophylla suscetível (S) e com resistência múltipla a inibidores da ALS e PROTOX (RM), e o fator B correspondeu à aplicação de herbicidas fomesafen e lactofen isolados ou em associação com inseticida organofosforado metamidofós, e testemunha sem aplicação. O biótipo $S$ apresentou maior fitotoxicidade, redução de massa verde e seca em relação ao biótipo RM. No biótipo RM, não houve diferença entre os tratamentos herbicidas, independentemente da associação ou não com o inseticida na maioria das variáveis analisadas. Estes resultados indicam que a associação do inseticida organofosforado metamidofós a herbicidas inibidores da PROTOX não aumenta os níveis de controle do biótipo RM em comparação à aplicação isolada desses herbicidas. Apesar de não serem definitivos, os resultados parecem indicar que a metabolização não é o mecanismo de resistência de E. heterophylla aos herbicidas inibidores da PROTOX.
\end{abstract}

Palavras-chave: Fomesafen; lactofen; glutationa-s-transferase; Citocromo $\mathrm{P}_{450}$

\begin{abstract}
Herbicide metabolization is one of the mechanisms that confers herbicide resistance to weeds. Organophosphate insecticides inhibits enzymes responsible for the metabolization of herbicides. This work was carried out to analyse if the metabolization of PROTOX inhibiting-herbicides is the cause of resistance in a multiple resistance biotype of Euphorbia heterophylla. The trial was carry out with a completely randomized experimental design; the treatments were organized in a factorial scheme with 4 repetitions. The factor A was composed by one E. heterophylla biotype susceptible (S) and one multiple resistant to PROTOX and ALS-inhibitors (MR) and the factor B was composed by the application of fomesafen and lactofen herbicides isolated or in tank-mixture with the organophosphate insecticide metamidophos, and an untreated-check. The $\mathrm{S}$ biotype presented greater injury and fresh-weight reduction in relation to MR biotype. In MR biotype, there was not difference between the herbicide treatments, regardless of the association with the insecticide in the several evaluations. These results indicate that the combination of organophosphate insecticide metamidophos to PROTOX inhibiting-herbicides does not increase the levels of control of MR biotype compared to isolated application of these herbicides. While not definitive, the results seem to indicate that the metabolism is not the mechanism of resistance of E. heterophylla to the PROTOX inhibiting-herbicides.
\end{abstract}

Key-words: Fomesafen; lactofen; glutationa-s-transferase; Cytochrom $\mathrm{P}_{450}$

\footnotetext{
${ }^{1}$ Engenheiro Agrônomo. Dr. Professor do Curso de Agronomia da Universidade Tecnológica Federal do Paraná, Campus Pato Branco, Pato Branco, Paraná, Brasil. E-mail: trezzi@utfpr.br

${ }^{2}$ Engenheiro Agrônomo. Doutorando do Programa de Pós Graduação em Fitotecnia da Faculdade de Agronomia da Universidade Federal do Rio Grande do Sul (UFRGS), Av. Osvaldo Aranha, 340, apto 513, CEP 90035-190. Porto Alegre, Rio Grande do Sul, Brasil. E-mail: nunes.ander@gmail.com Autor para correspondência

${ }^{3}$ Engenheiro Agrônomo.Mestre, Universidade Federal do Rio Grande do Sul (UFRGS), Porto Alegre, Rio Grande do Sul, Brasil. E-mail: edsportes@gmail.com
} 
TREZZI, M.M. et al. Interação entre inseticida organofosforado e herbicidas...

\section{INTRODUÇÃO}

A leiteira (Euphorbia heterophylla L. EPHHL) é uma espécie daninha alógama cujo centro de origem está compreendido na região Brasil-Paraguai (Kissmann \& Groth, 1992). Essa espécie está amplamente distribuída no Centro-Sul do Brasil. Cada dez plantas de leiteiro $\mathrm{m}^{-2}$ reduz em $7 \%$ o rendimento de grãos de soja (Glycine max (L.) Merr) quando o período de convivência com a cultura ocorre durante todo o ciclo (Chemale \& Fleck, 1982). O controle de EPHHL através de herbicidas seletivos é realizado principalmente com inibidores das enzimas acetolactato sintase (ALS) e protoporfirinogênio oxidase (PROTOX) (Vidal \& Merotto Júnior, 2001). Contudo, na última década, identificaram-se nessa espécie biótipos resistentes aos inibidores de ALS, principalmente nos estados do Rio Grande do Sul, Paraná, São Paulo e Mato Grosso do Sul e no Paraguai (Vidal \& Merotto Júnior, 1999; Trezzi et al., 2005; Heap, 2008). Também foram identificados biótipos com resistência múltipla a inibidores da ALS e da PROTOX (Trezzi et al., 2005) e, atualmente, ao glyphosate (Vidal et al., 2007). A resistência, principalmente a múltipla, dificulta ou pode inviabilizar o controle químico desta espécie, devido à falta de herbicidas disponíveis para o seu controle.

Os mecanismos que determinam a resistência de plantas daninhas a herbicidas estão relacionados, principalmente, aos processos de absorção e/ou translocação dos herbicidas, ao local de ação alterado, ou mesmo ao processo de metabolização dos herbicidas pelas plantas (Vidal, 1997). Estudos com biótipo de EPHHL com resistência apenas a inibidores da ALS, em que foi isolada essa enzima, constataram atividade enzimática muito menor, em relação à do biótipo suscetível, o que indica que a resistência é causada por alteração no local de ação da enzima ALS (Oliveira et al., 2002). No entanto, até o momento, não são conhecidos os mecanismos de resistência dos biótipos de EPHHL com resistência múltipla a inibidores da ALS e PROTOX.

A enzima PROTOX está localizada nos cloroplastos e mitocôndrias (Watanabe et al., 2001) e atua na rota de síntese de porfirinas, sendo a responsável pela oxidação de protoporfirinogênio IX, transformando-o em protoporfirina IX (Lehnen et al., 1990). Protoporfirina IX é um composto fotodinâmico (Lehnen et al., 1990), que é responsável pela formação de clorofila e citocromos através de reações com $\mathrm{Mg}$ e $\mathrm{Fe}$, respectivamente (Vidal \& Merotto Júnior, 2001). Além disso, protoporfirina IX é essencial para a formação de catalases e peroxidases, que são importantes na redução de estresse de diferentes origens, devido à habilidade de inativar radicais livres (Chaudière \& Ferrari-lliou, 1999). A ação herbicida ocorre pela competição pela enzima PROTOX entre o herbicida e o substrato (protoporfirinogênio IX). Como o herbicida possui maior afinidade com a enzima do que o substrato, protoporfirinogênio IX acumula no cloroplasto e difunde para o citoplasma, onde é rapidamente oxidado a protoporfirina IX (Jacobs et al., 1991; Lee et al., 1993). Uma vez no citoplasma, protoporfirina IX não pode voltar ao cloroplasto e reagir com $\mathrm{Mg}$ e $\mathrm{Fe}$, porque é altamente lipofílica (Lehnen et al., 1990). E assim, na presença de luz e oxigênio, protoporfirina IX gera oxigênio singleto, que causa peroxidação da membrana celular e, conseqüentemente, necrose dos tecidos e morte das plantas (Becerril \& Duke, 1989; Jacobs et al., 1991).

Tanto a tolerância quanto a resistência a herbicidas inibidores da PROTOX, em diversas espécies, ocorre através de vários mecanismos. No amendoim (Arachis hypogaea L. var. Starr), a tolerância ao fluorodifen é atribuída à mínima translocação, associada à rápida metabolização (Eastin, 1971). Em ervilha (Pisum sativum L.), alta concentração da enzima glutationa-s-transferase é responsável pela tolerância ao fluorodifen, pois ela age aumentando a conjugação deste herbicida (Frear \& Swanson, 1973). Na cultura da soja, após absorção pelas raízes e translocação até as folhas, sulfentrazone é rapidamente metabolizado, antes que o produto possa causar danos à planta (Dayan et al., 1997). Em células de soja, a resistência ao oxyfluorfen foi selecionada devido a aumento da concentração da enzima PROTOX nas mitocôndrias, que possibilitou maior habilidade no uso do excesso de protoporfirina IX presente no citoplasma (Warabi et al., 2001). Patzoldt et al. (2006) verificaram que a resistência de caruru (Amaranthus tuberculatus) deve-se a uma mutação em um gene nuclear que confere mudanças em dois locais de ação presentes na mitocôndria e no cloroplasto. No arroz transgênico, a super expressão de genes responsáveis pela geração da enzima PROTOX, proveniente da bactéria Myxococcus xanthus, garante a resistência desta espécie aos herbicidas inibidores da PROTOX (II Jung \& Kuk, 2007).

A tolerância ou resistência por metabolização ou desintoxicação do herbicida na planta ocorre devido à presença de enzimas monooxigenases $\left(\mathrm{P}_{450}\right)$ e de glutationa-stransferase, responsáveis por reações de oxidação e conjugação do herbicida, respectivamente (Vidal, 2002). Neste mecanismo de resistência, a magnitude da metabolização varia conforme a espécie, estádio de desenvolvimento da planta e do ambiente. Este mecanismo é encontrado em plantas resistentes aos herbicidas inibidores de ACCase, inibidores de ALS, inibidores do fotossistema I (FS I), inibidores de FS II, inibidores de enol-piruvil shiquimato fosfato sintase (EPSPs), inibidores da divisão celular e auxinas sintéticas (Powles \& Holtum, 1994; Christoffoleti, 2003). Caso o mecanismo de resistência esteja relacionado a metabolização do herbicida, a planta resistente possui a capacidade de decompor ou metabolizar a molécula mais rapidamente do que plantas sensíveis, tornando-a inativa (Vargas \& Fleck, 1999). Logo, se a causa da resistência é a maior metabolização do herbicida, o uso de um inibidor da 
TREZZI, M.M. et al. Interação entre inseticida organofosforado e herbicidas...

metabolização associado ao herbicida ao qual a planta apresenta resistência, deverá ser capaz de interromper a resistência. Inseticidas organofosforados são capazes de inibir a enzima citocromo $\mathrm{P}_{450}$, principal responsável pela metabolização de alguns grupos de herbicidas (Tardif \& Powles, 1999). Trabalhos realizados para avaliar o mecanismo da resistência de capim-arroz (Echinochloa spp.) ao herbicida propanil, indicaram que a resistência deste biótipo deve-se a metabolização do herbicida através da atividade da enzima aril-acylamidase (Leah et al., 1995). A aplicação de inseticidas, juntamente com 0 herbicida propanil, inibe a atividade das enzimas que detoxificam os herbicidas em plantas resistentes (Leah et al., 1995), e assim as plantas são controladas.

Este trabalho partiu da premissa de que inseticidas organofosforados, como metamidofós, são capazes de inibir a enzima citocromo $\mathrm{P}_{450}$, a principal responsável pela metabolização de alguns grupos de herbicidas (Tardif \& Powles, 1999). Se a metabolização for 0 principal mecanismo de resistência, a inibição da enzima citocromo $P_{450} \mathrm{com}$ inseticidas deverá aumentar a injúria às plantas nos biótipos de EPHHL com resistência múltipla a inibidores da ALS e PROTOX. O objetivo desse trabalho foi verificar se a metabolização é o provável mecanismo de resistência a inibidores da PROTOX em uma população de E. heterophylla com resistência múltipla a inibidores da ALS e da PROTOX.

TABELA 1 - Herbicidas, inseticida e associações de herbicidas e inseticidas aspergidos sobre biótipos de Euphorbia heterophylla suscetível e resistente aos herbicidas inibidores da PROTOX e ALS para a avaliação da metabolização como mecanismo de resistência aos inibidores da PROTOX.

\begin{tabular}{lc}
\hline \multicolumn{1}{c}{ Tratamentos } & $\begin{array}{c}\text { Dose } \\
(\mathrm{g} \mathrm{i.a} \mathrm{ha-1)}\end{array}$ \\
\hline Testemunha & 0 \\
Metamidofós (inseticida) & 300 \\
Fomesafen & 240 \\
Fomesafen + metamidofós & $240+300$ \\
Lactofen & 250 \\
Lactofen + metamidofós & $250+300$ \\
\hline
\end{tabular}

Os tratamentos foram aspergidos quando as plantas de EPHHL apresentavam duas folhas verdadeiras (estádio de estrelinha), através de equipamento pressurizado com gás carbônico, com bicos 110.02. O volume de calda foi de $150 \mathrm{dm}^{3} \mathrm{ha}^{-}$ 1 . Foram realizadas avaliações de controle aos 7 , 14 e 21 dias após aspersão (DAA) dos herbicidas. Aos 21 DAA, foi determinada a matéria verde e seca das plantas. Para a avaliação de controle foi utilizada escala visual que varia de $0 \%$, para nenhum controle, a $100 \%$, para a morte das plantas. Os dados coletados foram submetidos à análise da variância, através do teste $F$ e, em caso de significância, foi realizada comparação de

\section{MATERIAL E MÉTODOS}

O presente trabalho foi conduzido em casa de vegetação do curso de Agronomia da Universidade Tecnológica Federal do Paraná (UTFPR), localizada em Pato Branco (PR) em junho de 2007. As sementes dos biótipos resistente (biótipo \#23) (Trezzi et al., 2005) e suscetível foram coletadas, respectivamente, em 2003 e 2006, nos municípios de Vitorino (ano de 2003) e Renascença (ano de 2006), ambos localizados na região Sudoeste do estado do Paraná. Foram semeadas dez sementes de Euphorbia heterophylla (EPHHL) suscetível ou com resistência múltipla em vasos plásticos com capacidade de $1000 \mathrm{~cm}^{3}$ de solo. Quinze dias após a emergência das plântulas, foi realizado desbaste, padronizando em cinco o número de plântulas por vaso. O delineamento experimental utilizado foi 0 completamente casualizado, com os tratamentos organizados em esquema fatorial, com quatro repetições, onde 0 fator A representou os biótipos de EPHHL (suscetível e resistente) e o fator $\mathrm{B}$ o uso de inseticida, herbicida ou associação entre herbicida e inseticida (Tabela 1). Foi utilizado o inseticida metamidofós como inibidor da enzima $P_{450}$. Nos tratamentos que continham herbicidas foi adicionado $3 \mathrm{~cm}^{3} \mathrm{dm}^{-3}$ de do espalhante adesivo Energic. A escolha dos herbicidas fomesafen e lactofen ocorreu em função da sua maior utilização na região Sudoeste do Paraná. médias pelo teste de Tukey a $5 \%$ de probabilidade do erro experimental.

\section{RESULTADOS E DISCUSSÃO}

Em todas as avaliações efetuadas, o uso de lactofen e fomesafen, independentemente da associação ou não com o inseticida metamidofós, resultou em níveis de controle superiores no biótipo de EPHHL suscetível, em relação ao resistente (Tabela 2). Em média, os níveis de controle das plantas do biótipo suscetível exercidos por fomesafen ou lactofen, em comparação ao biótipo com resistência múltipla foram 73,50 e $72 \%$ maiores, respectivamente, nas avaliações aos 7, 14 
TREZZI, M.M. et al. Interação entre inseticida organofosforado e herbicidas...

e 21 DAA. Para o biótipo de EPHHL com resistência múltipla, os níveis de controle proporcionados por fomesafen, lactofen e suas associações a metamidofós não diferiram entre si (Tabela 2). No entanto, para o biótipo suscetível, observou-se controle um pouco inferior na aplicação de fomesafen isoladamente, nas avaliações aos 7 e 21 DAA, em relação aos demais tratamentos herbicidas ou associações desses a metamidofós.

TABELA 2 - Níveis de controle dos biótipos de Euphorbia heterophylla, aos 7, 14 e 21 dias após a aplicação (DAA), em resposta a diferentes tratamentos de herbicida aplicado isolado ou em associação com inseticida organofosforado.

\begin{tabular}{|c|c|c|c|c|c|c|c|c|c|c|c|c|c|c|}
\hline \multirow{3}{*}{$\begin{array}{l}\text { Tratamentos } \\
\text { Testemunha }\end{array}$} & \multicolumn{2}{|c|}{ Controle (\%) aos 7 DAA } & \multicolumn{6}{|c|}{ Controle (\%) aos 14 DAA } & \multicolumn{6}{|c|}{ Controle (\%) aos 21 DAA } \\
\hline & Resist $^{1}$. & Suscet. & \multicolumn{3}{|c|}{ Resist. } & \multicolumn{3}{|c|}{ Suscet. } & \multicolumn{3}{|c|}{ Resist. } & \multicolumn{3}{|c|}{ Suscet. } \\
\hline & 0 a $B^{2}$ & 0 a C & $\overline{0}$ & $\mathrm{a}$ & $\mathrm{D}$ & 0 & $\bar{a}$ & $B$ & 0 & $a$ & $\mathrm{C}$ & 0 & $\bar{a}$ & $\bar{D}$ \\
\hline Metamidofós & 7 a $B$ & 12 a $\mathrm{C}$ & 12 & a & C & 17 & a & $B$ & 12 & b & $B$ & 18 & a & C \\
\hline Lactofen & $23 \mathrm{~b} \quad \mathrm{~A}$ & 97 a $\mathrm{A}$ & 35 & $b$ & B & 90 & a & $A$ & 30 & b & $A$ & 100 & a & $A$ \\
\hline Lac. + metam. & $22 \mathrm{~b} \quad \mathrm{~A}$ & 97 a $\mathrm{A}$ & 43 & $b$ & $A B$ & 95 & a & $A$ & 25 & b & $A$ & 98 & a & $A$ \\
\hline Fomesafen & $26 \mathrm{~b} \quad \mathrm{~A}$ & 77 a $B$ & 55 & $b$ & A & 85 & a & $A$ & 25 & b & $A$ & 75 & & $\mathrm{~B}$ \\
\hline Fom. + metam. & $28 \quad b \quad A$ & 93 a $A$ & 50 & $b$ & A & 93 & a & $A$ & 23 & b & $A$ & 95 & a & $A$ \\
\hline C.V\% ${ }^{1}$ & & & & & 5 , & & & & & & & & & \\
\hline $\operatorname{DMS}(T)^{1}$ & & & & & 11 & & & & & & & & & \\
\hline DMS $(B)^{1}$ & & & & & 9, & & & & & & & & & \\
\hline
\end{tabular}

${ }^{1}$ Abreviaturas: Resist = Resistente; Suscet. = Suscetível; Lac = Lactofen; metam. = Metamidofós; Fom. = Fomesafen; C.V\% = Coeficiente de variação; DMS $(\mathrm{T})$ = Diferença mínima significativa para as médias dos tratamentos dentro de cada biótipo; DMS $(B)=$ Diferença mínima significativa para as médias dos biótipos dentro de cada tratamento.

2 Médias seguidas por letras maiúsculas comparam tratamentos dentro de cada biótipo. Médias seguidas por letras minúsculas comparam os biótipos dentro de cada tratamento pelo teste de Tukey a $5 \%$.

Os dois biótipos apresentaram tolerância ao inseticida quando aplicado isolado, mas os níveis de toxicidade ao biótipo suscetível foram superiores, em comparação ao resistente na avaliação aos 21 dias (Tabela 2). Nas avaliações aos 7 e 21 DAA, os níveis de controle do biótipo suscetível, proporcionados por fomesafen, foram ampliados na associação a metamidofós, em comparação ao seu uso isolado (Tabela 2). O efeito tóxico do inseticida ao biótipo de EPHHL suscetível determinou a ampliação dos níveis de controle desse biótipo proporcionados pelo herbicida menos eficaz (fomesafen), sem, no entanto ampliar os níveis de controle de lactofen, pois estes já eram elevados (Tabela 2). A adição de metamidofós aos herbicidas fomesafen e lactofen não resultou em ampliação dos níveis de controle do biótipo resistente.

Em geral, os sintomas observados nas plantas de EPHHL suscetíveis aspergidas com esses herbicidas foram clorose, necrose, redução do crescimento, epinastia e enrugamento das folhas. Já, no biótipo resistente foram clorose, necrose e redução do crescimento, em menor intensidade que no biótipo suscetível. Ainda, no biótipo resistente, verificou-se que os danos restringiram-se às folhas, mas não se verificaram danos sobre o caule e a capacidade de rebrote. Aos 16 DAA, iniciou intenso rebrote no biótipo resistente, gerando folhas levemente cloróticas. Aos 18 DAA, as folhas do biótipo resistente que sofreram danos pelo contato com o herbicida recuperaram-se e reiniciaram 0 seu desenvolvimento. Esse efeito pode ser observado na comparação entre as médias de controle aos 21 e 14 DAA (Tabela 2).

As matérias seca e verde e estatura das plantas do biótipo resistente foram, respectivamente, 54, 87 e $64 \%$ superiores às do biótipo suscetível e não houve redução dessas variáveis através da associação de fomesafen e lactofen a metamidofós (Tabela 3), ou seja, houve correspondência dos resultados obtidos com os resultados de níveis de controle (Tabela 2 ).

A comparação com a testemunha indica que ambos os biótipos foram afetados pelo uso dos herbicidas ou associações, só que o biótipo de EPHHL com resistência múltipla foi afetado em proporção bem menor do que o biótipo suscetível (Tabelas 2 e 3). Os resultados de controle, estatura, matérias verde e seca do biótipo com resistência múltipla indicam que a resistência apresentada não é absoluta, embora os danos causados às plantas pelas doses de herbicidas e associações utilizadas no presente experimento não sejam suficientes para comprometer definitivamente 0 desenvolvimento das mesmas. 
TREZZI, M.M. et al. Interação entre inseticida organofosforado e herbicidas...

TABELA 3 - Matéria verde e seca e estatura dos biótipos de Euphorbia heterophylla, aos 21 dias após a aplicação (DAA), em resposta a diferentes tratamentos de herbicida aplicado isolado ou em associação com inseticida organofosforado.

\begin{tabular}{|c|c|c|c|c|c|c|c|c|}
\hline \multirow{3}{*}{$\begin{array}{l}\text { Tratamentos } \\
\text { Testemunha }\end{array}$} & \multicolumn{3}{|c|}{$\begin{array}{l}\text { Matéria verde } \\
\left(\mathrm{mg} \mathrm{planta}^{-1}\right)\end{array}$} & \multicolumn{3}{|c|}{$\begin{array}{l}\text { Matéria seca } \\
\left(\mathrm{mg} \mathrm{planta}^{-1}\right)\end{array}$} & \multicolumn{2}{|c|}{$\begin{array}{c}\text { Estatura } \\
(\mathrm{cm})\end{array}$} \\
\hline & \multicolumn{2}{|c|}{ Resist $^{1}$. } & Suscet. & \multicolumn{2}{|c|}{ Resist. } & Suscet. & Resist. & Suscet. \\
\hline & 129 & $\mathrm{a} \mathrm{A}^{2}$ & 124 a $\mathrm{A}$ & $91 \mathrm{a}$ & $A$ & 92 a $A$ & 20 a A & 19 a $A$ \\
\hline Metamidofós & 110 & a A & 87 b $B$ & $81 \mathrm{a}$ & $A$ & 63 b B & 19 a $A B$ & $15 \mathrm{~b} A$ \\
\hline Lactofen & 69 & a B & $33 \mathrm{~b} \quad \mathrm{c}$ & $45 a$ & $\mathrm{~B}$ & $4 \mathrm{~b} \mathrm{C}$ & 14 a C & 5 b $B$ \\
\hline Lac. + metam. & 71 & a B & 31 b $c$ & $51 \mathrm{a}$ & $\mathrm{B}$ & $4 \mathrm{~b} \mathrm{C}$ & 12 a $C$ & 4 b $B$ \\
\hline Fomesafen & 63 & a B & $24 \mathrm{~b} \quad \mathrm{C}$ & $52 \mathrm{a}$ & B & 9 b C & 15 a $B C$ & 5 b $B$ \\
\hline Fom. + metam. & 58 & a B & 31 b c & $47 \mathrm{a}$ & B & $9 \mathrm{~b} C$ & 14 a C & $6 \mathrm{~b} \quad \mathrm{~B}$ \\
\hline$\overline{C . V \%}{ }^{1}$ & \multicolumn{3}{|c|}{4,3} & \multicolumn{3}{|c|}{9,1} & \multicolumn{2}{|c|}{3,6} \\
\hline $\operatorname{DMS}(\mathrm{T})^{1}$ & \multicolumn{3}{|c|}{25,6} & \multicolumn{3}{|c|}{15,0} & \multicolumn{2}{|c|}{4,5} \\
\hline $\mathrm{DMS}(\mathrm{B})^{1}$ & \multicolumn{3}{|c|}{15,2} & \multicolumn{3}{|c|}{8,4} & \multicolumn{2}{|c|}{2,4} \\
\hline
\end{tabular}

Abreviaturas: Resist $=$ Resistente; Suscet. $=$ Suscetível; Lac = Lactofen; metam. = Metamidofós; Fom. = Fomesafen. C.V\% = Coeficiente de variação; DMS $(\mathrm{T})$ = Diferença mínima significativa para as médias dos tratamentos dentro de cada biótipo; DMS $(B)=$ Diferença mínima significativa para as médias dos biótipos dentro de cada tratamento.

${ }^{2}$ Médias seguidas por letras maiúsculas comparam tratamentos dentro de cada biótipo. Médias seguidas por letras minúsculas comparam os biótipos dentro de cada tratamento pelo teste de Tukey a $5 \%$.

O fato da adição de inseticida organofosforado não incrementar definitivamente os níveis de controle no biótipo de EPHHL resistente, em ambos os experimentos, pode ser um indicativo que a metabolização diferencial não é o principal mecanismo de resistência a inibidores da PROTOX em biótipos que apresentam resistência múltipla aos herbicidas inibidores da ALS e da PROTOX. Estes resultados foram semelhantes aos obtidos em biótipos de caruru (Amaranthus rudis) com resistência múltipla a herbicidas inibidores da ALS e PROTOX, em que foi demonstrado que os herbicidas acifluorfen e lactofen, associados aos inseticidas malathion ou diazinon, causaram o mesmo nível de dano às plantas, quando comparados à aplicação isolada desses herbicidas (Shoup et al., 2003).

Por outro lado, é possível que o inseticida organofosforado empregado (metamidofós) não seja o melhor inibidor da enzima $P_{450}$, que seria responsável pela putativa metabolização dos herbicidas inibidores da PROTOX no biótipo com resistência múltipla (Baerg et al., 1996; Ferhatoglu et al., 2005).

Outros trabalhos avaliaram o efeito de inseticidas organofosforados sobre outros mecanismos de ação de herbicidas. Em biótipos de capim-arroz (Echinochloa spp.) resistentes ao herbicida propanil (inibidor do fotossistema II), constatou-se que o herbicida foi eficaz no controle das plantas quando aspergido em associação a inseticida (Leah et al., 1995). Oliveira et al. (2002) utilizando biótipo de EPHHL com resistência apenas a inibidores da ALS, isolaram essa enzima e constataram atividade muito menor, em relação à enzima do biótipo suscetível, o que indica que a resistência é causada por alteração no local de ação da enzima ALS. Acredita-se que este também seja o mecanismo de resistência a inibidores da ALS no biótipo de EPHHL com resistência múltipla. No entanto, o mecanismo que confere resistência aos herbicidas inibidores da PROTOX nesse biótipo permanece desconhecido.

Vários trabalhos sugerem que podem haver vários mecanismos atuando concomitantemente para conferir resistência aos herbicidas inibidores da PROTOX (Eastin, 1971; Frear \& Swanson, 1973; Dayan et al., 1997; Warabi et al., 2001; Shoup et al., 2003). Entre os possíveis mecanismos que atuam em conjunto na resistência aos herbicidas inibidores da PROTOX estão a redução da absorção e translocação, a rápida destruição do protoporfirinogênio IX ou protoporfirina IX no citoplasma e local de ação alterado. Outros experimentos, comparando os biótipos de EPHHL com resistência múltipla e suscetível estão buscando determinar se há diferenças de controle devido à absorção diferencial dos herbicidas inibidores da PROTOX.

\section{CONCLUSÕES}

A associação do inseticida organofosforado metamidofós a herbicidas inibidores da PROTOX não aumenta os níveis de controle obtidos pela aplicação isolada desses herbicidas, no biótipo de $E$. heterophylla com resistência múltipla aos herbicidas inibidores da ALS e da PROTOX. 
TREZZI, M.M. et al. Interação entre inseticida organofosforado e herbicidas...

\section{AGRADECIMENTOS}

Os autores agradecem ao Conselho Nacional de Desenvolvimento Cientifico e Tecnológico (CNPq) e Fundação Araucária e aos alunos de graduação da Faculdade de Agronomia da UTFPR Mara Stoco Gustmann, Edson Franchim, Rafael Pedroso da Silva, Edemir Miotto Jr. e Felipe Patel.

\section{REFERÊNCIAS}

1. BAERG, R. J.; BARRETT, M.; POLGE, N. D. Insecticide and insecticide metabolite interactions with cytochrome $P_{450}$ mediated activities in maize. Pesticide Biochemistry and Physiology, v. 55, n. 1, p. 10-20, 1996.

2. BECERRIL, J. M.; DUKE, S. O. Protoporphyrin IX content correlates with activity of photobleaching herbicides. Plant Physiology, v. 90, n. 3, p.1175-1181, 1989.

3. CHAUDIËRE, J.; FERRARI-ILIOU, R. Intracellular antioxidants: From chemical to biochemical mechanisms. Food and Chemical Toxicology, v. 37, n. 9-10, p. 949-962, 1999.

4. CHEMALE, V. M.; FLECK, N. G. Avaliação de cultivares de soja (Glycine max (L.) Merril) em competição com Euphorbia heterophylla L. sob três densidades e dois períodos de ocorrência. Planta Daninha, v. 5, n. 2, p. 36-45, 1982.

5. CHRISTOFFOLETI, P. J. Aspectos de resistência de plantas daninhas a herbicidas. 2. ed. Londrina: HRAC-BR, 2003. $90 \mathrm{p}$.

6. DAYAN, F. E. et al. Soybean (Glycine max) cultivar differences in response to sulfentrazone. Weed Science, v. 45, n. 4, p. 634-641, 1997.

7. EASTIN, E. F. Fate of fluorodifen in resistant peanut seedlings. Weed Science, v. 19, n. 2, p. 261-265, 1971.

8. FERHATOGLU, Y.; AVDIUSHKO, S.; BARRETT, M. The basis for the safening of clomazone by phorate insecticide in cotton and inhibitors of cytochrome P450s. Pesticide Biochemistry and Physiology, v. 81, n. 1, p. 59-70, 2005.

9. FREAR, D. S.; SWANSON, H. R. Metabolism of substituted diphenyl ether herbicides in plants. I. Enzymatic cleavage of fluorodifen in peas (Pisum sativum L.). Pesticide Biochemistry Physiology, v. 3, n. 4, p. 473-482, 1973.

10. HEAP, I. Herbicide resistant wild poinsettia globally. Disponível em <http://www.weedscience.org/Case/Case.asp?ResistlD=5294>. Acesso em: 15 fev. 2008.

11. II JUNG, H.; KUK, Y. I. Resistance mechanisms in protoporphyrinogen oxidase (PROTOX) inhibitor-resistant transgenic rice. Journal of Plant Biology, v. 50, n. 5, p. 586-594, 2007.

12. JACOBS, J. M. et al. Effect of diphenyl ether herbicides on oxidation of protoporphyrinogen to protoporphyrin in organella and plasma membrane enriched fractions of barley. Plant Physiology, v. 97, n. 1, p. 197-203, 1991.

13. KISSMANN, K. G.; GROTH, D. Plantas infestantes e nocivas. 1. ed. São Paulo: Basf Brasileira, 1992. 603 p.

14. LEAH, J. M. et al. Age-related mechanisms of propanil tolerance in jungle-rice, Echinochloa colona. Pesticide Science, v. 43, n. 4, p. 347-354, 1995.

15. LEE, H. J.; DUKE, M. V.; DUKE, S. O. Cellular localization of protoporphyrinogen-oxidizing activities of etiolated barley (Hordeum vulgare) leaves (Relationship to Mechanism of Action of Protoporphyrinogen Oxidase-Inhibiting Herbicides). Plant Physiology, v. 102, n. 3, p. 881-889, 1993.

16. LEHNEN, L. P. et al. O. Tissue and cellular localization of acifluorfen-induced porphyrins in cucumber cotyledons. Pesticide Biochemistry Physiology, v. 37, n. 3, p. 239-248, 1990.

17. OLIVEIRA, M. F. et al. Atividade da acetolactato sintase de plantas de milho e de amendoim-bravo (Euphorbia heterophylla) resistentes e suscetíveis ao imazaquin. Planta Daninha, v. 20, n. 1, p. 77-82, 2002.

18. PATZOLDT, W. L. et al. A codon deletion confers resistance to herbicides inhibiting protoporphyrinogen oxidase. Proceedings of the National Academy of Sciences of the United States of America, v. 103, n. 33, p. 12329-12334, 2006.

19. POWLES, S.; HOLTUM, J. Herbicide resistance in plants: biology and biochemistry. New York: CRC Press, 1994. 368 p.

20. SHOUP, E. D.; AL-KHATIB, K.; PETERSON, D. E. Common waterhemp (Amaranthus rudis) resistance to protoporphyrinogen oxidase-inhibiting herbicides. Weed Science, v. 51, n. 2, p. 145-150, 2003

21. TARDIF, F. J.; POWLES, S. B. Effect of malathion on resistance to soil-applied herbicides in a population of rigid ryegrass. Weed Science, v. 47, n. 3, p. 258-261, 1999.

22. TREZZI, M. M. et al. Multiple resistance to acetolactate synthase and protoporphyrinogen oxydase inhibitors in Euphorbia heterophylla biotypes. Journal of Environmental Science and Health part B, v. 40, n. 1, p. 101-109, 2005.

23. VARGAS, L; FLECK, N. G. Seletividade de herbicidas do grupo químico dos ariloxifenoxipropionatos a cereais de inverno. Planta Daninha, v. 17, n. 1, p. 41-51, 1999.

24. VIDAL, R. A. Herbicidas: mecanismo de ação e resistência de plantas. Porto Alegre: R. A. VIDAL, 1997. 165 p.

25. VIDAL, R. A. Ação dos herbicidas: absorção, translocação e metabolização. Porto Alegre: Evangraf, 2002. 89 p.

26. VIDAL, R. A.; MEROTTO JÚNIOR, A. Herbicidologia. Porto Alegre: Evangraf, 2001. 152 p.

27. VIDAL, R. A.; MEROTTO JÚNIOR, A. Resistência de amendoim-bravo aos herbicidas inibidores da enzima acetolactato sintase. Planta Daninha, v. 17, n. 3, p. 367-373, 1999.

28. VIDAL, R. A. et al. Glyphosate resistant biotypes of wild poinsettia (Euphorbia heterophylla L.) and its risk analysis on glyphosate-tolerant soybeans Journal of Food, Agriculture and Environment., v. 5, n. 2, p. 265-269, 2007.

29. WARABI, E. et al. Resistance of a soybean cell line to oxyfluorfen by overproduction of mitochondrial protoporphyrinogen oxidase. Pest Management Science, v. 57, n. 8, p.743-748, 2001

30. WATANABE, N. et al. Dual targeting of spinach protoporphyrinogen oxidase II to mitochondria and chloroplasts by alternative use of in-frame initiation codons. Journal of Biological Chemistry, v. 276, n. 23, p. 20447-20481, 2001.

Recebido em 11/04/2008 Aceito em 10/06/2009 